\title{
AS MULHERES E SUAS ‘LIDAS’: COMPREENSÕES ACERCA DE TRABALHO E SAÚDE
}

\author{
WOMEN AND THEIR CHORES: HOW WORK AND HEALTH ARE UNDERSTOOD
}

LAS MUJERES Y SUS LIDES: COMPRENSIONES ACERCA DE TRABAJO Y SALUD

\author{
Sandra Beatris Diniz Ebling ${ }^{1}$ \\ Elza Maria Fonseca Falkembach ${ }^{2}$ \\ Lizandra Andrade Nascimento ${ }^{3}$ \\ Marciele Moreira da Silva ${ }^{4}$ \\ Silvana de Oliveira Silva ${ }^{5}$ \\ Patrícia Stangherlin Minussi ${ }^{6}$
}

Resumo Trata-se de um estudo de natureza qualitativa, de caráter exploratório e descritivo, desenvolvido em um assentamento rural do Movimento dos Trabalhadores Rurais Sem Terra da região centro-ocidental do Rio Grande do Sul. Busca apresentar e discutir as concepções das mulheres assentadas em relação ao trabalho no interior do assentamento, abordando suas implicações na saúde da mulher. Os dados foram reunidos no decorrer de 2011, com nove mulheres residentes no assentamento, por meio de entrevista semiestruturada. Com base na análise temática, os resultados indicaram que o trabalho da mulher assentada é amplo e nem sempre reconhecido. No que se refere à saúde, constatou-se que as cidadãs na condição de assentadas estão expostas a vulnerabilidades, pois vivem em um espaço no qual o trabalho é eminentemente braçal, expostas aos fenômenos e instabilidades da natureza. Outra constatação resultante da pesquisa é a ampliação do espaço de participação da mulher nos negócios da família, inclusive com linhas de crédito específicas para as agricultoras, o que contribui para a emancipação feminina. Portanto, parece relevante a união de esforços no sentido de ampliar ações que subsidiem a elaboração de políticas públicas abrangentes ao contexto da realidade em que essas mulheres se inserem.

Palavras-chave assentamento; trabalho; mulheres; saúde.
Abstract This is a qualitative, exploratory, and descriptive study carried out in a rural settlement of the Landless Rural Workers' Movement in the mid-western region of Rio Grande do Sul, Brazil. It aims to present and discuss the views settled women have with regard to the work done within the settlement, addressing implications for women's health. The data were gathered in 2011 through semi-structured interviews conducted among nine women living in the settlement. Based on the analysis of the theme, the results indicated that the work done by settled women is broad and not always recognized. With regard to health, it was found that female settled citizens are exposed to vulnerabilities, because they live in an area where work is eminently manual and are exposed to the weather and other instabilities of nature. Another finding is the expansion of women's space of participation in the family business, including specific credit lines for female farmers, factors contributing to the emancipation of women. Therefore, it seems relevant to join efforts to expand actions that support the development of comprehensive public policies to address the reality of the context in which these women are located.

Keywords settlement; work; women; health. 


\section{Introdução}

Debater movimentos sociais significa pensar em ações sociais coletivas, de traços sociopolíticos e culturais que possibilitem novas formas de os sujeitos se organizarem, "articulando ações coletivas que agem como resistência à exclusão e lutam pela inclusão social" (Gohn, 2003, p. 15). Dentre tais movimentos, o Movimento dos Trabalhadores Rurais Sem Terra (MST), no Brasil, apresenta-se como um espaço de resistência à histórica acumulação característica do capitalismo. Por isso, torna-se imprescindível compreender como se organizam no espaço conquistado o 'assentamento', principalmente no que tange às mulheres, 7 e suas 'lidas' .

A condição de mulher no espaço do MST abrange as dificuldades no acesso às informações e ações de saúde, as quais se relacionam às desigualdades das relações de gênero; às grandes distâncias entre a residência ou o trabalho e os serviços de saúde; e ao acesso a tais serviços. Todos esses elementos relacionam-se com a pouca sensibilização e a fragilidade da rede de saúde para trabalhar com a especificidade dos agravos derivados do trabalho no campo (Brasil, 2004).

$\mathrm{O}$ adoecimento e a morte de cada indivíduo revelam os impactos e consequências das desigualdades sociais, econômicas e culturais. De acordo com os indicadores de saúde, as populações expostas a frágeis condições de vida estão mais vulneráveis e vivem menos.

Nesse sentido, o Relatório do Fundo de População das Nações Unidas de 2002 traça um panorama sobre a condição da mulher, demonstrando que, em relação aos homens, o número de mulheres que vivem em situação de pobreza é superior, assim como o número de horas que as mulheres trabalham é maior. Este estudo destaca que metade do tempo das mulheres é gasto em atividades não remuneradas, o que diminui o seu acesso aos bens sociais, inclusive aos serviços de saúde (Brasil, 2004).

São muitos os estudos que, na atualidade, abordam o tema da mulher rural. 8 Entretanto, esperamos avançar em relação aos estudos meramente biologicistas da mulher, buscando compreender as especificidades da vida no assentamento e direcionando as análises para as relações das mulheres no contexto do trabalho e saúde.

Assim, dentre as questões a serem discutidas, está a complexidade do trabalho feminino, no que se refere à jornada e à multiplicidade de tarefas desempenhadas pela mulher. Estudos desenvolvidos por Schwendler (2006), Salvaro (2004) e Melo (2001) salientam a dupla ou tripla jornada de trabalho da mulher assentada, mostrando que, no final do dia de atividades na lavoura, ela ainda tem a preocupação com os afazeres do domicílio, o cuidado com as crianças e, nesse entremeio, se depara com as atividades de militante na luta social. 
Vale salientar que os afazeres domésticos, comumente, não são reconhecidos como trabalho. A esse respeito, Schwendler argumenta que

mesmo a mulher participando do trabalho produtivo, este é muitas vezes visto como uma 'ajuda'. Da mesma forma, quando o homem realiza alguma atividade no lar, ele também estaria 'ajudando' a mulher" (Schwendler, 2006, p. 2).

As atividades ditas femininas e as tarefas ditas masculinas são aprendidas e transmitidas como 'naturais' entre muitos assentados e assentadas. Mesmo em espaços de lutas por mudanças sociais, atitudes conservadoras interferem fortemente na definição do modo de se tornar homem ou mulher em nossa sociedade. Com base nas questões mencionadas, este artigo busca apresentar e discutir as concepções das mulheres assentadas em relação ao trabalho no interior do assentamento, abordando suas implicações na saúde da mulher.

\section{Caminho metodológico}

O presente estudo 9 é de natureza qualitativa, de caráter exploratório e descritivo, desenvolvido em um assentamento rural do MST localizado no interior da região centro-ocidental do Rio Grande do Sul, o qual se localiza a 498 quilômetros da capital. Os sujeitos da pesquisa foram nove mulheres selecionadas com os seguintes critérios de inclusão: ter idade igual ou superior a 18 anos, residir há mais de três anos no assentamento em estudo e ter vontade de partilhar suas experiências por meio das entrevistas.

A coleta de dados foi realizada no período de março a maio de 2011, com o acompanhamento da agente comunitária de saúde, no domicílio das participantes e de acordo com a disponibilidade delas. Para a coleta das informações utilizou-se a entrevista semiestruturada, objetivando promover a interação entre as mulheres entrevistadas e a entrevistadora. Os depoimentos foram gravados e posteriormente transcritos na íntegra, mediante autorização dos sujeitos. Apresentou-se a eles um termo de consentimento livre e esclarecido, contendo os objetivos, a metodologia e explicações sobre a livre participação, a preservação do sigilo e o respeito à liberdade de participar ou não da pesquisa.

A produção dos dados ocorreu até o momento em que eles começaram a apresentar redundância, isto é: a definição do número de participantes se deu por saturação de dados - compreendida como o momento em que a busca de novos sujeitos não adiciona nenhum elemento novo ao estudo (Minayo, 2010).

A análise temática dos dados seguiu os passos de pré-análise, exploração do material, tratamento dos resultados obtidos e interpretação (Minayo, 2010). Inicialmente, as entrevistas passaram por um processo de organização, leitura, releitura e construção de agrupamentos dos depoimentos em torno das 'ideias' ou 
temas centrais de análise, visando à compreensão do objeto de análise. O estudo dos depoimentos oportunizou a construção de categorias que ordenaram a análise.

Com o intuito de garantir o anonimato, os depoimentos foram identificados pela letra S (sujeito), seguida por indicadores numéricos que sinalizam a sequência das entrevistas. Exemplo: S1 (sujeito número 1), S2 etc.

A pesquisa recebeu a aprovação do Comitê de Ética em Pesquisa da Universidade Regional do Noroeste do Estado do Rio Grande do Sul (Unijuí), Ijuí, Rio Grande do Sul, Brasil, conforme o protocolo n. 0110/2009. Este estudo respeitou as determinações da resolução n. 196/96 do Conselho Nacional de Saúde.

\section{As mulheres e suas vozes}

As mulheres assentadas expressam, por meio de sua voz, questões a elas dirigidas pela entrevistadora, as quais serão apresentadas no decorrer do artigo. Ressaltamos que os dados apresentados, resumidamente, visam constituir uma breve caracterização do universo de participantes deste estudo, descrevendo de forma panorâmica as suas condições de escolaridade, origem geográfica, formas de composição de arranjos familiares e experiência de maternidade. 10

O grupo de entrevistadas constituiu-se por mulheres na faixa etária dos 35 aos sessenta anos, oriundas de Nonoai, Ronda Alta, Tenente Portela, Miraguaí, Palmeira das Missões, Cruz Alta, Joia, Ibirubá, Trindade, Boa Vista do Incra, Rodeio Bonito, Bom Progresso, Seberi e São José das Missões, dentre outros municípios do estado do Rio Grande do Sul. Na sua maioria, são descendentes de pequenos agricultores de origem "luso-brasileira, alemã, italiana e, também, provenientes de famílias numerosas" (Instituto Brasileiro de Geografia e Estatística, 2006). Dessa maneira, o grupo se caracteriza pela diversidade cultural, sendo território de encontro de pessoas advindas de localidades diferentes e, consequentemente, de culturas, tradições e costumes diversos.

Quanto à escolaridade, a maioria possui ensino fundamental incompleto. As entrevistadas relatam experiências de escolarização marcadas pelas constantes mudanças de município, em razão de seu pertencimento aos acampamentos do MST, bem como pelas vivências de exclusão social.

No que tange às histórias de constituição de suas famílias, também verificamos uma grande diversidade. Algumas das entrevistadas relatam os desafios enfrentados como mães solteiras; outras residem com seus cônjuges, dividindo com estes as responsabilidades pelo sustento da família e o cuidado com os filhos; há ainda as que relatam as vivências da separação, a partir da qual passam a constituir novos arranjos familiares com outros companheiros.

Nesses vários tipos de constelações familiares, há um traço comum, com base nas falas das entrevistadas: é a preocupação com a criação dos filhos e 
a garantia de que estes possam ter acesso à educação e a melhores condições de vida. Assim, constata-se que praticamente todas vivenciam a experiência da maternidade, tendo em média três filhos.

No que concerne à saúde, as entrevistadas referem como principal problemática dores lombares, depressão e cefaleia, que acometem muitas delas. Um ponto a ser destacado, nesse contexto, são os cuidados tomados em relação à saúde, pois antes de buscarem atendimento na unidade de saúde, elas recorrem aos chás e medicamentos caseiros. Somente quando os sintomas se agravam buscam assistência na unidade. Esse procedimento é aplicado a elas mesmas e, também, aos familiares.

As informações decorrentes das vozes dessas mulheres foram distribuídas em três categorias temáticas: 'A mulher assentada do Movimento Sem Terra', 'A mulher e a lida' e 'A mulher, educação, saúde e gênero'. O foco aqui é a categoria 'A mulher e a lida', subdividida em: a mulher e a 'lida' no contexto da saúde, que será apresentada a seguir.

\section{A mulher e a 'lida'}

O termo 'lida' remete às atividades rotineiras desenvolvidas pelas mulheres assentadas, as quais envolvem as tarefas domésticas e o trabalho rural (atividades de agricultura e pecuária) na busca de subsistência.

Como essa foi uma expressão marcante ao longo das entrevistas e dos diálogos estabelecidos com as assentadas, fomos em busca de seus muitos significados. Lida pode ser compreendida como a ação de lidar, como labor, faina, trabalho prolongado, acúmulo de serviços, azáfama, pressa, grande afã. Essa multiplicidade de significados nos propiciou pensar sobre o cotidiano de todos os indivíduos na sociedade, em que nos vemos compelidos a 'lidar' cada vez mais para dar conta das numerosas demandas geradas pelo progresso científico e tecnológico, pela complexificação do mundo do trabalho, pela globalização. Enfim, o cenário contemporâneo configura-se pela complexidade de relações, em que as pessoas parecem estar em permanente corrida atrás de promessas sempre novas da indústria e da cultura.

No caso das mulheres, essas lidas são ainda mais amplas e nem sempre reconhecidas, pois elas precisam lidar com as tarefas domésticas, a escolaridade e os cuidados com os filhos, a saúde (própria e do grupo familiar), as contas a pagar, os financiamentos específicos. Para as mulheres assentadas, incluem-se também as lidas com a lavoura e as questões políticas do MST. Tais constatações são corroboradas pelas visões das entrevistadas sobre a lida. Umas falam das suas atividades com orgulho, outras reclamam do trabalho excessivo, como verificamos em seus depoimentos: 
Eu levanto às cinco e meia, boto o relógio pra despertar, porque o meu guri vai pra aula. Aí às 6 horas (...) tem que estar na estrada e daí eu já começo a luta... Faço fogo, faço um chimarrão, boto a água na térmica, me vou lá para a estrebaria pra tirar leite, daí, depois que tiro o leite, guardo o leite, vou levar as vacas pro pasto, atamos os terneiros na soga, também vou mudar e, assim, vou indo e daí venho pra dentro tomar meu cafezinho (...) que daí às oito eu tenho outra lida, eu de novo vou pra fora. E daí eu vou deixando a casa por último. (...) Daí, depois que eu faço as outras lidas lá pra fora, eu venho pra dentro, dou uma arrumada na casa, como se diz, e vou fazer o almoço (S5).

Eu acordo às seis horas (...) Seis horas da manhã eu vou tirar leite, daí solto as vacas no pasto, dou água para o terneiro, trato os porcos e as galinhas e daí depois venho pra dentro, faço pão (...) Daí começo a preparar a comida para as crianças ir para o colégio (...) (S3).

Após os relatos, evidencia-se que ser mulher, mãe, esposa e trabalhadora rural requer das mulheres assentadas a disposição para assumir numerosas atividades ao mesmo tempo. Ao ouvi-las, nossa sensação é a de certeza de que não deve ser fácil assumir tantas posições e enfrentar uma rotina extenuante de trabalho. Muitos questionamentos nos vêm à mente durante suas falas: qual é o espaço reservado para si, para as suas questões pessoais, numa rotina que começa às cinco e meia da manhã?

Todas essas indagações e reflexões nos permitem concluir que não é por acaso que as entrevistadas denominam sua rotina de luta (S5: “e daí eu já começo a luta..."). Ou seja, seu dia a dia é realmente uma luta, procurando articular tantas atividades ao mesmo tempo.

Segundo Antunes (2007), é por meio do trabalho que o ser humano se constitui como humano; e com o desenvolvimento e o aprimoramento do trabalho, de suas técnicas e instrumentos, é que vai ser possível a evolução da espécie. Por meio do trabalho se dá a satisfação das necessidades humanas, bem como a possibilidade de conforto e bem-estar.

Para Arendt (2010), o trabalho é a atividade que corresponde ao artificialismo da existência humana. Ele produz um mundo 'artificial' de coisas, nitidamente diferente de qualquer ambiente natural. Dentro de suas fronteiras, conforme Arendt (2010), habita cada vida individual, embora esse mundo se destine a sobreviver e a transcender todas as vidas individuais. A condição humana do trabalho é ser mundano - o que leva à suposição de que o trabalho possibilita ao ser humano constituir um espaço comum, no qual estabelece sua presença. Para tanto, torna-se necessário que a atividade de trabalho tenha significado, para que os indivíduos possam se reconhecer e reservar momentos para as demais instâncias da vida, indicadas por Arendt (2010) como o pensar, o querer, o julgar e o agir. 
No processo de entrevistas, as mulheres demonstram os distintos significados assumidos pelo trabalho por elas executado, apresentando as diferenças entre a vida no acampamento e o cotidiano no assentamento, conforme o depoimento a seguir:

Nós também ia [sic] pras granjas, assim, cevar milho, pipoca, ajuntar batatinha, que eles arrancavam e nós ia [sic] ajuntando e ensacando... Feijão também. Só que no feijão eu não fui nenhuma vez, meu marido foi umas quantas vezes na arranca de feijão (...) Agora é diferente. É outra vida, depois que a gente ganhou a terra, fizemos uma casinha de madeira ali... Daí a gente trouxe também as coisas que a gente tinha lá fora. Daí o fogão também, mas o fogão a lenha não trouxemos pra cá. Agora tem só fogão a gás aqui. E aqui foi um pouco, pra mim, uma casa, só que não tinha caimento, a vertente da água, daí nós tinha [sic] que só com o balde no poço... Daí depois que veio a luz, sim... Primeira coisa foi comprar uma motobomba pra tirar água do poço para trazer pra dentro de casa. Pra lavar roupas e tudo. Agora já tem água de poço artesiano, está bem melhor agora (S4).

Relatos como esse revelam os avanços obtidos a partir da condição de mulheres assentadas, quando conseguem se estruturar e obter melhores oportunidades de trabalhar e, consequentemente, ter mais conforto e bem-estar, como referido por Antunes (2007). Assim, por mais dura que seja a rotina no assentamento, somando-se os cuidados com a família e a casa às atividades agrícolas, essa realidade é menos árdua do que a vivenciada na condição de acampados, quando ainda na luta pela conquista da terra. Conquistar a terra significa conseguir um espaço onde se possa existir como ser humano e desenvolver ações de trabalho e de sobrevivência.

Paralelamente às atividades cotidianas, da 'lida', percebemos que o envolvimento com o MST traz marcas específicas, relacionadas com a política e a cidadania, como bem ilustra o depoimento de uma das entrevistadas, que assim se refere:

Eu tenho muito orgulho de fazer parte do MST (...), não participava antes. Então, assim, então eu tenho muito orgulho, em todo lugar que eu vou, eu faço questão de dizer que eu moro no assentamento. Geralmente eu ando com camiseta, boné, material do movimento (S8).

Partindo do pressuposto de que cidadania é uma intervenção coletiva, é uma visão de mundo, como afirma Freire (2000), observamos que a participação efetiva no MST propicia às mulheres a vivência da cidadania, no sentido de luta por direitos sociais, para além da questão da terra. Ainda conforme Freire, 
as chamadas minorias precisam reconhecer que, no fundo, elas são a maioria. O caminho para assumir-se como maioria está em trabalhar as semelhanças entre si e não só as diferenças, e assim criar a unidade na diversidade, fora da qual não vejo como aperfeiçoar-se e até como construir-se uma democracia substantiva, radical (Freire, 2000, p. 56).

Integrar um grupo minoritário ou em situação de vulnerabilidade requer o engajamento das mulheres no movimento e traz consequências, percebidas na configuração de um orgulho por fazer parte desse processo e contar com a cooperação de outros indivíduos na luta por direitos básicos e pela melhoria da qualidade de vida. Na fala da entrevistada, constatamos a visão particular da importância da participação, do movimento de saída da esfera doméstica para a inclusão no espaço público e nas lutas do MST.

Foi assim, saiu uma reunião ali embaixo e até foi chamada a mulherada, era pra esse outro, esse curso de saúde da mulher. Daí a M. ali debaixo, que é a coordenadora nossa, ela disse: 'Vamos fazer uma reunião', daí vamos falar do Pronaf e não tinha esse Pronaf, não era nada de dinheiro. Mas daí pra juntar a mulherada falaram que era... Pra ganhar dinheiro todo mundo vai... Chegamos lá, nem foi tocado nesse assunto, nós estava [sic] na pauta, mas daí depois foi discutido junto. Daí decidiram, tinham alguns homens por lá também... Aqui... Daí na hora foi resolvido de nós pegar... Arrumar um ônibus, um micro-ônibus, e pegar uma turma de mulher, era para ser algumas e depois fomos todas. Quarenta e poucas mulheres no Banco do Brasil, e daí lá escolhemos um grupo para entrar e as outras ficaram lá fora, qualquer coisa entravam também... pra resolver o tal financiamento. Não que tinha esse Pronaf, é um Pronaf assim ... Daí conseguimos, era de 1.500 só, mas conseguimos. Já foi um jeito de organizar as mulheres (S6).

Participar do MST contribui para que as mulheres extrapolem o espaço doméstico, passando a exercer posições de protagonistas no trabalho e na busca de financiamento para avançar em termos de subsistência e diversificação da produção agroecológica. Isso lhes possibilita se contraporem à tendência tradicional de tornar invisível o trabalho da mulher.

Para Faria e Nobre (2003), a economia das mulheres é invisível até porque o mercado criou condições para os homens, não pensando nelas. Nesse mesmo mercado, as mulheres tiveram que se adequar e conciliar as tarefas domésticas com o trabalho em âmbito público. Por essa razão, conciliar as numerosas atividades do lar com as atividades desenvolvidas fora de casa e, ainda, obter linhas de crédito específicas para mulheres representam uma conquista importante - não apenas em termos de visibilidade, mas, sobretudo, para que as mulheres se percebam como produtoras de riqueza, como capazes de 
sobreviver com autonomia e contribuir para a melhoria da qualidade de vida de sua família e de seus grupos de convivência no assentamento.

Trata-se de um elemento salutar para o processo de emancipação das mulheres, pois, além da tomada de consciência da relevância de seu papel e da ampliação do espaço por elas ocupado, as mulheres assentadas se dão conta de que é necessário continuar avançando na luta por seus direitos.

O MST se apresenta, pois, como espaço oportuno para o exercício da cidadania, posto que, como já mencionamos, o movimento aglutina sujeitos oriundos de diversas localidades e realidades, mas todos unidos em torno de um objetivo comum. Assim, o MST apresenta essa possibilidade de abertura indispensável para a cidadania, uma vez que articula indivíduos que vivenciaram situações de exclusão na busca conjunta de alternativas para a superação dessas condições. Contudo, não apenas as mulheres, mas os indivíduos como um todo apresentam dificuldades de exercer suas posições de cidadãos, pois os anos de opressão deixam marcas nos sujeitos, muitas vezes silenciando suas vozes. Assim, para que as mulheres possam exercer a cidadania, no contexto do assentamento, torna-se necessário dar-lhes a oportunidade de participação ativa nos processos de tomada de decisão.

Segundo Conte (2011), somente quando a mulher conseguir superar a identidade subalterna e se colocar como um ser que vale tanto quanto outro será possível falar em igualdade de gênero. Para tanto, é necessário desconstruir sua inferiorização e invisibilidade. Muitos passos já foram dados na direção dessa desconstrução necessária. Porém, é preciso continuar caminhando. Torna-se indispensável insistir no processo de emancipação.

Nesse sentido, trabalho (lida) e educação são fatores imprescindíveis para a emancipação. O trabalho pode ser agente transformador e emancipador, desde que seja ressignificado, valorizando as potencialidades do indivíduo e colocando-o como autor de sua trajetória, e não como mera peça na engrenagem capitalista. O trabalho pode ter caráter libertador desde que não obedeça à lógica da produtividade e da acumulação preconizada pelo neoliberalismo. Para tanto, precisa ser uma atividade consciente do indivíduo, na qual ele aja com objetivos claros de produção de melhores condições de vida para os demais, buscando a adesão de suas necessidades com respeito ao ambiente e sem se tornar escravo do consumo (Antunes, 2007).

A educação, por seu turno, pode contribuir para o pleno desenvolvimento do indivíduo, para a construção da liberdade pessoal e para a formação humana permanente, por meio do acesso aos conhecimentos historicamente acumulados, possibilitando-lhe conhecer o mundo e compreender suas contradições, pensando em alternativas para a transformação social.

Emancipar-se significa, para Adorno (2000), tomar decisões conscientes e independentes, por meio de uma consciência verdadeira, sendo ainda um dos 
nexos de uma sociedade verdadeiramente democrática. Nas circunstâncias vivenciadas na sociedade moderna, cada vez mais emancipação se torna sinônimo de abstração, necessitando de inserção no pensamento e na prática educativa, pois é importante o enfrentamento da organização do mundo e dos vieses ideológicos que superam a educação e limitam as possibilidades emancipatórias.

Portanto, emancipação supõe conscientização, racionalidade e, ao mesmo tempo, adaptação dos homens ao mundo, no sentido de ensejar orientações para que esses homens e mulheres se situem no mundo. Nesse ínterim, a educação emancipatória tem o papel de desenvolver princípios individuais e sociais (adaptação e resistência), buscando fortalecer a resistência mais que as condições de adaptação dos humanos.

Ao se emanciparem, as mulheres podem se unir na resistência ao projeto político dominante, buscando, juntamente com os demais integrantes do movimento, a constituição de um poder político verdadeiramente cidadão, em que todos tenham direitos igualitários, em que sejam assegurados os direitos individuais e coletivos, num projeto de sociedade mais humana.

O contato com as mulheres assentadas e a escuta de seus relatos sobre a 'lida', as conquistas, dificuldades, desencantos e esperanças nos trazem parâmetros para pensar os avanços já alcançados e os desafios a serem enfrentados para aproximar o real e o ideal, isto é, para materializar esse novo projeto de sociedade.

\section{A mulher e a 'lida' no contexto da saúde}

Nesta seção, procuramos compreender as implicações e a relevância de uma política de saúde destinada às mulheres que vivenciam as especificidades do MST na condição de assentadas. Nesse contexto, evidencia-se que os cidadãos e cidadãs, como assentados e assentadas, estão expostos a vulnerabilidades - no que se refere à saúde, tanto os homens como as mulheres, pois vivem em um espaço no qual o trabalho é eminentemente braçal, expostos aos fenômenos e instabilidades da natureza, principalmente no que tange a longas jornadas de trabalho com exposição ao sol.

Conforme o Ministério da Saúde,

As condições de saúde da população rural são determinadas por características relacionadas ao compasso de trabalho sazonal, aos processos de mobilidade dos acampamentos e assentamentos, à baixa escolaridade, à pobreza, às relações de trabalho e de gênero que contribuem para tornar os trabalhadores rurais mais vulneráveis a algumas enfermidades (Brasil, 2004, p. 53).

Tal situação é mais intensa para as mulheres que têm dupla jornada de trabalho, pois elas atuam diretamente nas tarefas da 'lida' do leite e da la- 
voura e articulam essas atividades com tarefas da casa, domésticas e de mãe, como pode ser evidenciado na fala a seguir.

Daí, de tarde depois de novo começa... Vai vaca pro pasto, porque nós botamos na sombra de meio-dia, daí no caso é sempre eu que lido... Daí vai [sic] as vacas de novo pro pasto... Porque eu tenho só um guri que está com 12 anos agora, daí ele vai pra lavoura junto com o esposo... E daí fica $[s i c]$ as vacas por minha conta. Os terneiros... Eu que lido com o leite. O leite é comigo e depois tem mais o serviço da casa... (S5).

Geralmente as mulheres se limitam ao espaço doméstico, da lavoura, vivenciando o cuidado com os filhos e a casa. Os espaços coletivos de tomada de decisão, na maioria das vezes, ainda são referidos ao homem.

Evidencia-se que ainda é frágil a inserção da mulher nos cenários coletivos de resolução de problemas, isto é, a participação das mulheres nos espaços decisórios, tais como em reuniões, congressos, cursos e até mesmo espaços referentes ao lazer.

De acordo com esse raciocínio, em relação às ações de cuidado diante das mulheres, elas necessitam ser diferenciadas. Não cuidamos do mesmo jeito de todas as mulheres. As ações voltadas à saúde da mulher devem levar em consideração aspectos referentes à singularidade, dentre os quais os credos, etnias, culturas, categorias socioeconômicas, sem os quais qualquer análise seria superficial ou incompleta. Por essa razão, Oliveira e Meyer (2005, p. 8) destacam a necessidade de considerarmos, além dos aspectos biológicos, as distinções das circunstâncias de vida das mulheres, ao passo que "mulheres diferentes têm necessidades diferentes de saúde".

Meyer (1999, p. 114) insiste na necessidade de questionarmos o caráter reducionista da expressão 'saúde da mulher', pois dele resulta uma definição de 'mulher' baseada apenas na sua especificidade biológica, negligenciando as diferenças de mulheres que estão inseridas no meio, portanto, sem contemplar a diversidade e a amplitude inerentes a gênero e saúde.

A fala a seguir de uma mulher assentada demonstra o anseio em receber orientações que vão além do olhar biológico. Quando questionada sobre sugestões de assuntos a serem debatidos no espaço do assentamento pelos profissionais da saúde, ela argumenta: "Eu acho que sobre tudo... Porque tem muitas coisas pra discutir, como vários assuntos da saúde da mulher, não só sobre o útero e o seio" (S6).

Nessa perspectiva, Boehs e colaboradores (2007) enfatizam a necessidade de que aqueles que atuam na saúde da mulher desenvolvam um conhecimento crítico que não se limite a questões baseadas, unicamente, nas dimensões biológicas - e propiciem espaço para que tanto o corpo biológico quanto o social sejam considerados. Desse modo, é possível dizer que as 
ações em saúde com mulheres assentadas necessitam proporcionar discussões e reflexões acerca da sua própria constituição como mulher, como sujeito ativo, inseridas num contexto sociocultural que carrega as especificidades do assentamento, o que precisa ser levado em conta no momento de ações educativas.

Em relação à saúde da mulher assentada, trabalhadora no meio rural, as especificidades e singularidades são claras, determinadas pelo complexo ritmo de trabalho sazonal e cíclico. Nesse sentido,

Perez, estudando um assentamento rural em determinada região no Brasil, chegou à conclusão que 'o modo de produção camponês do assentamento, influenciado por técnicas agrícolas de propriedades capitalistas rurais, com elevada utilização de insumos, produz uma presença significativa de fatores de deterioração da saúde'. Ficou evidente nesse trabalho uma participação diferenciada das mulheres na produção do assentamento e, por conseguinte, também na exposição e vulnerabilidade a esses fatores (Perez, 2001, apud Brasil, 2004, p. 55).

Referente aos agravos à saúde, a exposição aos agrotóxicos - seja ambiental, seja ocupacional, aguda ou crônica -, ao sol ou à chuva, dentre outras vulnerabilidades, constitui-se em particularidades que abrangem os agravos de saúde da população rural, podendo causar danos à saúde das mulheres trabalhadoras do campo. Quanto às questões de gênero, vale salientar que, no contexto geral da população residente e trabalhadora rural, faz-se necessário visualizar as condições restritivas referentes ao acesso da mulher à terra, à renda e ao crédito. O Censo da Reforma Agrária de 1996 registra que apenas $12,6 \%$ dos títulos de domínio ou de concessão de uso da terra são para as mulheres (Brasil, 2004). Segundo a mesma fonte, isso reflete de maneira clara questões como a desigualdade de gênero e afeta o acesso das mulheres das áreas rurais às políticas públicas.

\section{Considerações finais}

A pesquisa deu ênfase à realidade das mulheres assentadas que, hoje, conjugam jornadas de trabalho extenuantes, em que somam as atividades na lavoura, os afazeres da casa, o cuidado com as crianças e a militância na luta social. Esse é o retrato das mulheres com as quais desenvolvemos nossa pesquisa: mulheres de verdade, autênticas, diversas, complexas, desafiadoras e tão multifacetadas quanto as 'lidas' que realizam em seu dia a dia.

É pensando nessas mulheres e também nos homens que com elas convivem que precisam ser elaboradas as ações em saúde. Tal concepção deve ser aprofundada e ampliada quando se trata da mulher assentada, porque 
a sua condição de trabalhadora no meio rural traz especificidades que não podem ser negligenciadas. A exposição aos agrotóxicos, o trabalho pesado, o acúmulo de 'lidas', a exposição ao sol, a precariedade das instalações, a baixa escolaridade, a escassez de recursos financeiros, o acesso às vezes limitado à informação e a atendimentos especializados são alguns dos fatores a serem levados em consideração ao se pensar e propor saúde para as mulheres assentadas, e que nossos dados reafirmaram.

Ainda no que diz respeito às mulheres assentadas, uma constatação relevante da pesquisa que originou este artigo é a ampliação da participação da mulher nos negócios da família. A criação de linhas de crédito específicas para as agricultoras incrementou o poder decisório das mulheres em relação ao sustento da família. Embora essa se torne uma 'lida' a mais no seu cotidiano, é um fator importante para a autonomia e a emancipação feminina - porque, ao participarem efetivamente na área administrativa e econômica, as mulheres assentadas passam a ter mais 'voz e vez', ou seja, passam a agir politicamente com mais intensidade, superando a invisibilidade que as acompanhou por longos anos de submissão.

Diante das características predominantes em relação à saúde da mulher assentada, parece relevante a união de esforços para a construção de estratégias em saúde que atuem no sentido de ampliar e adequar ações que subsidiem a elaboração de políticas públicas abrangentes e adequadas ao contexto da realidade em que as mulheres se inserem.

\section{Colaboradores}

Sandra Beatris Diniz Ebling realizou a pesquisa bibliográfica, a análise dos dados e a elaboração do texto. Elza Maria Fonseca Falkembach atuou na análise dos dados e orientou a pes-quisa. Lizandra Andrade Nascimento, Marciele Moreira da Silva, Silvana de Oliveira Silva e Patrícia Stangherlin Minussi colaboraram na produção textual e na redação do artigo. 
Resumen Se trata de un estudio de naturaleza cualitativa, de carácter exploratorio y descriptivo, desarrollado en un asentamiento rural del Movimiento de los Trabajadores Rurales Sin Tierra de la región centro-occidental de Río Grande do Sul, Brasil. Buscar presentar y discutir las concepciones de las mujeres asentadas con relación al trabajo en el interior del asentamiento, abordando sus implicaciones en la salud de la mujer. Los datos fueron reunidos en el transcurso del 2011, con nueve mujeres residentes en el asentamiento, por medio de entrevista semiestructurada. En base al análisis temático, los resultados indicaron que el trabajo de la mujer asentada es amplio y no siempre reconocido. En lo que se refiere a la salud, se constató que las ciudadanas en la condición de asentadas están expuestas a vulnerabilidades, pues viven en un espacio en el cual el trabajo es eminentemente pesado, expuestas a los fenómenos e inestabilidades de la naturaleza. Otra constatación resultante de la investigación es la ampliación del espacio de participación de la mujer en los negocios de la familia, incluso con líneas de crédito específicas para las agricultoras, lo que contribuye para la emancipación femenina. Por lo tanto, parece relevante la unión de esfuerzos en el sentido de ampliar acciones que subsidien la elaboración de políticas públicas amplias al contexto de la realidad en que estas mujeres están insertadas.

Palabras clave asentamiento; trabajo; mujeres; salud.

\section{Notas}

1 Universidade Regional Integrada do Alto Uruguai e das Missões, Santiago, Rio Grande do Sul, Brasil.

<sandra.ebling@yahoo.com.br>

Correspondência: Rua Silveira Martins, 2.391, Centro, CEP 97700-000, Santiago, Rio Grande do Sul, Brasil.

2 Universidade Regional do Noroeste do Rio Grande do Sul, Programa de Pós-Graduação em Educação nas Ciências, Ijuí, Rio Grande do Sul, Brasil.

<elzaf@unijui.edu.br>

3 Universidade Regional Integrada do Alto Uruguai e das Missões, Campus São Luiz Gonzaga, Rio Grande do Sul, Brasil.

<zandranascimento@bol.com.br>

4 Universidade Regional Integrada do Alto Uruguai e das Missões, Santiago, Rio Grande do Sul, Brasil.

<enfmarciele@yahoo.com.br>

5 Universidade Regional Integrada do Alto Uruguai e das Missões, Santiago, Rio Grande do Sul, Brasil.

<silvanaoliveira@urisantiago.br>

6 Universidade Regional Integrada do Alto Uruguai e das Missões, Santiago, Rio Grande do Sul, Brasil.

$<$ patriciasminussi@gmail.com> 
7 O emprego da expressão 'as mulheres' ao longo do texto tem a ver com a pluralidade de sujeitos femininos mediante múltiplos atravessamentos, tais como raça, geração, etnia, classe, religião e gênero, dentre outros.

8 Ao longo da formação, tivemos contato com muitos referenciais pautados no viés puramente biológico, porém, para a elaboração deste estudo, procuramos superar essa visão fragmentada do ser humano. Buscamos embasamento em diversos estudos, dentre os quais os realizados por Isaura Conte (2011), Graciela Fabrício e do próprio Ministério da Saúde (Brasil, 2004), especialmente quando este define os princípios e as diretrizes da Política Nacional de Atenção Integral à Saúde da Mulher, constituindo visões abrangentes que contemplam uma visão global do sujeito mulher.

9 Este artigo foi extraído da dissertação As mulheres assentadas e suas lidas: compreensões acerca de gênero, educação, saúde e trabalho, de autoria de Sandra Beatris Diniz Ebling. Foi apresentada ao Programa de Mestrado em Educação nas Ciências da Unijuí, sob orientação da professora Elza Maria Fonseca Falkembach. Não há conflitos de interesse.

10 Os dados completos da pesquisa podem ser consultados na dissertação de mestrado As mulheres assentadas e suas lidas: compreensões acerca de gênero, educação, saúde e trabalho, disponível no sítio da Unijuí, em <www.unijui.edu.br/cursos/mestrado-e-doutorado/ educacao-nas-ciencias $>$.

\section{Referências}

ADORNO, Theodor W. Educação e emancipação. 2. ed. Tradução de Wolfgang Leo Maar. Rio de Janeiro: Paz e Terra, 2000.

ANTUNES, Ricardo. Os sentidos do trabalho: ensaio sobre a afirmação e a negação do trabalho. São Paulo: Boitempo Editorial, 2007.

ARENDT, Hannah. A condição humana. 10. ed. Rio de Janeiro: Forense Universitária, 2010.

BOEHS, Astrid E. et al. A interface necessária entre enfermagem, educação em saúde e o conceito de cultura. Texto \& Contexto Enfermagem, Florianópolis, v. 16, n. 2, p. 307-314, 2007.
BRASIL. Ministério da Saúde. Secretaria de Atenção à Saúde. Departamento de Ações Programáticas Estratégicas. Política Nacional de Atenção Integral à Saúde da Mulher: princípios e diretrizes. Brasília: Ministério da Saúde, 2004. <http://bvsms.saude.gov. br/bvs/publicacoes/politica_nac_atencao_ mulher.pdf>. Data de acesso: jun. 2011.

CONTE, Isaura I. Mulheres camponesas em luta: resistência, libertação e empoderamento. Dissertação (Mestrado em Educação nas Ciências) - Universidade Regional do Noroeste do Estado do Rio Grande do Sul, Ijuí, RS, 2011. 
FABRÍCIO, Graciela. Mulheres assentadas e suas vozes. Dissertação (Mestrado em Educação nas Ciências) - Universidade Regional do Noroeste do Estado do Rio Grande do Sul, Ijuí, RS, 2009.

FARIA, Nalu; NOBRE, Miriam (org.). A produção do viver: ensaios de economia feminista. São Paulo: SOF. Espaço de Sophia, vol. 15, ano II, jun. 2003. p. 01-210.

FREIRE, Paulo. Pedagogia da esperança. São Paulo: Paz e Terra, 2000.

GOHN, Maria G. Movimentos sociais: manifestações e categorias analíticas. In: GOHN, Maria G. (org.). Movimentos sociais no início do século XXI: antigos e novos atores sociais. Petropólis: Vozes, 2003. p. 01-200.

INSTITUTO BRASILEIRO DE GEOGRAFIA E ESTATÍSTICA (IBGE). Cadastro Central de Empresas. 2006. Tabela 1735. Dados gerais das unidades locais por faixas de pessoal ocupado total, segundo seção da classificação de atividades, em nível Brasil, Grandes Regiões, Unidades da Federação e Municípios, 2006. Disponível em: <www.sidra.ibge.gov.br/ $\mathrm{bda} / \mathrm{tabela} /$ protabl.asp $\mathrm{c}=1735 \& \mathrm{z}=\mathrm{t} \& \mathrm{o}=$ $1 \& \mathrm{i}=\mathrm{P}>$. Acesso em: jun. 2011.

MELO, Elizabete J. Gênero e jornada de trabalho em assentamentos rurais. Revista Pegada Eletrônica, São Paulo, v. 2, n. 2, p. 1-29, out. 2001.
MEYER, Dagmar E. Saúde da mulher: indagações sobre a produção do gênero. O Mundo da Saúde, São Paulo, v. 23, n. 2, p. 113-118, 1999.

MINAYO, Maria C. S. O desafio do conhecimento: pesquisa qualitativa em saúde. São Paulo: Hucitec; Abrasco, 2010.

OLIVEIRA, Dora L.; MEYER, Dagmar E. Gênero e saúde das mulheres. In: OLIVEIRA, Dora L. (org.). Enfermagem na gravidez, parto e puerpério: notas de aula. Porto Alegre: Editora da UFRGS, 2005.

PEREZ, Marco S. G. O trabalho doente entre assentados rurais. Dissertação (Mestrado em Saúde Coletiva) - Departamento de Medicina Preventiva e Social, Universidade Estadual de Campinas, Campinas, SP, 2001

SALVARO, Giovana I. J. Jornadas de trabalho de mulheres e homens em assentamento do MST. Dissertação (Mestrado em Educação) - Universidade Federal de Santa Catarina, Florianópolis, SC, 2004.

SCHWENDLER, Sônia F. As relações de gênero e a educação de jovens e adultos nos assentamentos de reforma agrária. SEMINÁRIO INTERNACIONAL FAZENDO GÊNERO, 2006. Anais. Disponível em: <www.fazendogenero. ufsc.br/7/artigos/S/Sonia_Fatima_Schwendler_ 58.pdf $>$. Acesso em: maio 2011.

Recebido em 05/02/2013

Aprovado em 05/03/2014 